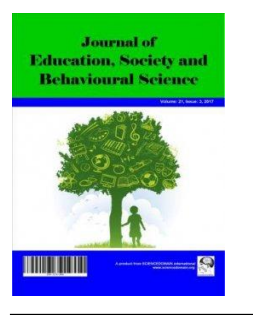

Journal of Education, Society and Behavioural Science

27(2): 1-19, 2018; Article no.JESBS.44445

ISSN: 2456-981X

(Past name: British Journal of Education, Society \& Behavioural Science,

Past ISSN: 2278-0998)

\title{
Attitudes to Training and Their Relation to the Well- being of Workers
}

\author{
Norshaffika I. Zaiedy Nor $^{1 *}$ and Andrew P. Smith ${ }^{1}$ \\ ${ }^{1}$ Centre for Occupational and Health Psychology, School of Psychology, Cardiff University, \\ 63 Park Place, Cardiff, CF10 3AS, United Kingdom.
}

Authors' contributions

This work was carried out in collaboration between both authors. Authors NIZN and APS designed the study. Author NIZN performed the statistical analysis, wrote the protocol and wrote the first draft of the manuscript. Author APS managed the analyses of the study. Both authors read and approved the final

manuscript.

Article Information

DOI: $10.9734 / J E S B S / 2018 / 44445$

Editor(s):

(1) Dr. Faika Sanal Karahan, Assistant Professor, Department of Guidance and Psychological Counseling, Faculty of

Education, Usak University, Turkey. Reviewers:

(1) Ibrahim El-Zraigat, The University of Jordan, Jordan.

(2) Wasilu Suleiman, Bauchi State University, Nigeria.

(3) Hakan Usakli, Sinop University, Turkey.

Complete Peer review History: http://www.sciencedomain.org/review-history/26681

Original Research Article

Received 03 August 2018

Accepted 12 October 2018

Published 19 October 2018

\section{ABSTRACT}

Background: This study aimed to investigate the influence of attitudes towards training on individuals' level of well-being, after controlling for other variables (demographics and psychosocial characteristics). Attitudes towards training consist of motivation to learn, learning, transfer intention and cognitive dissonance.

Methodology: In total, 210 workers who had undergone various training programs completed an online survey measuring various psychosocial characteristics, four training attitudes and level of well-being.

Results: The results showed that positive psychosocial characteristics (positive personality, positive coping, positive work characteristics, organisational citizenship behaviours and commitment) had significant associations with positive attitudes towards training (motivation to learn, learning and transfer intention) and positive well-being. Similarly, negative psychosocial characteristics (negative coping and negative work characteristics) were correlated with negative training attitudes (cognitive dissonance) and negative well-being. The training attitudes also had a moderate to high correlation 
with well-being. However, after controlling for other variables (age, gender, education and psychosocial characteristics), only cognitive dissonance was found to influence negative well-being. Cognitive dissonance theory was used to explain these findings.

Conclusion: This study gives a new perspective in the field of both training and well-being. It not only provides new knowledge but may also be beneficial to practitioners. More research is required in the future to confirm the link between training attitudes and well-being and examine in more depth the relationship between them.

Keywords: Cognitive dissonance; learning; transfer intention; motivation to learn; psychosocial characteristics; well-being.

\section{INTRODUCTION}

Training is essential to develop individuals' expertise to meet current and future job demands and improve work performance [1]. At the same time, individuals' well-being is crucial to ensure that they can fully and positively carry out their daily duties. In addition to studies that have examined what constitutes well-being and the factors behind it, many researchers have investigated the predictors of training effectiveness and transfer of training. However, there has been very little integration between them. This study is an attempt to bridge the gap between training effectiveness predictors and well-being.

\subsection{Well-being}

Well-being is often associated with the experience of pleasure and the absence of pain over time [2]. However, Ryff and Singer [3] claimed that well-being is much more than that. Well-being comprises an individual's sense of self-acceptance, positive relationship with others, display of autonomous functioning, environmental mastery and having a purpose in life and optimal personal growth [3].

Research on well-being began decades ago, and many researchers have examined the antecedents of well-being, ranging from personal to work-related characteristics [4-10]. Initially, many researchers found that certain types of personality traits played a role in determining individuals' level of well-being. Personality is defined as individual differences in general patterns of cognition, emotion and behaviour [11], and these patterns evolve from both biological and environmental factors [12]. Examinations of the connection between personality and well-being have been conducted among various populations [13-21]. Research has found that those who have high conscientiousness tend to have high life satisfaction [22-24], along with the personality traits of agreeableness [23,24] and extraversion $[22,23]$. Meanwhile, those with high neuroticism may experience more anxiety and depression [23], and low psychological well-being [25,26]. Liu, Li, Ling and Cai [27] added that individuals' inclination to encounter positive affect and their extraversion traits result in them forming optimistic expectancies, and therefore increase their level of well-being.

Apart from personality, coping strategies also play a role in predicting individuals' levels of wellbeing. Coping is defined as an individual's constant effort to manage specific internal or external demands that are perceived as surpassing that individual's resources [28]. It was found that a more active and positive coping strategy, for example, problem-solving, seeking social support, using cognitive restructuring or taking positive and planned action, may help boost individuals' psychological well-being $[29,30]$ and decrease depression [31]. On the other hand, a more passive or negative coping strategy, such as problem avoidance, social withdrawal, self-criticism, emotional discharge or seeking alternative rewards, will lead to increased feelings of depression [31] and distress [32]. It was revealed that when individuals experienced high stress, their mental health decreased. This was not the case with those who frequently applied positive coping methods, such as positive re-interpretation and humour, which help prevent poor mental health [33].

Apart from personal characteristics, work-related variables also play a role in determining individuals' levels of well-being. There is much evidence to support the relationship between commitment and well-being. Mowday, Steers and Porter [34] defined commitment as an individual's loyalty towards the organisation, consisting of an active relationship with the organisation, with individuals willing to give something for its sake. 
Employees with high commitment to the organisation also reported having a good level of well-being $[4,35]$. In addition, affective and continuance commitment, which are the dimensions of organisational commitment proposed by Meyer and Allen [36], could moderate the relationship between job-related anxiety and intention to leave an organisation [37]. Glazer and Kruse [37] found that nurses experiencing a high level of affective and continuance commitment were less influenced by job-related anxiety in terms of intention to leave a hospital. This result may have been due to the effect of commitment, which provided a meaningful relationship with the organisation; hence, when employees' commitment was high, this commitment would make them accept the anxiety caused by work stressors and would reduce the justification for the intention to leave [37].

Another work-related variable that can influence well-being is organizational citizenship behaviour (OCB). Organ [38] defined OCB as 'individual behaviour that is discretionary, not directly or explicitly recognised by the formal reward system and that in the aggregate promotes effective functioning of the organisation' (p. 4). He has proposed five taxonomies of OCB: 1) conscientiousness, for example, employees following the rules and attending meetings and/or social gatherings, 2) courtesy, for example employees who respect others by consulting with other people before taking any action, 3) altruism, reflecting helping behaviour, 4) sportsmanship, for example avoiding trivial matters such as gossiping and complaining about small matters, and 5) civic virtue, which represents always updating aspects which affect an organisation. Boyd and Nowell [39] revealed that OCB directed towards both the organisation and individuals is positively associated with individuals' levels of psychological well-being. However, Bolino, Turnley and Niehoff [40] have suggested that OCB may have a dark side, proposing that OCBs could derive from selfserving motives. For example, an employee might perform an OCB to impress their employer or management, or the employee might have more mundane motives, such as exhibiting OCB due to boredom with their own job/task or helping others because they want to cover their counterproductive work behaviour. Bolino and Turnley [41] found that one type of OCB action, termed individual initiative, consisting of behaviour such as coming to work early and staying late, working during vacation, rearranging personal plans because of work, and so on, was related to higher levels of role overload and job stress and to an increase in work-family conflict. Thus, as Bolino and colleagues [42] suggest, researchers should not only focus on the positive but also any potential negative consequences of OCB.

With regard to job characteristics, the motivational elements that effect and define the meaningfulness, responsibility, and knowledge relating to work activities that are experienced by the employee [43] were found to influence various well-being outcomes. Research has found that workers who possess high levels of job latitude or control and who receive better social support from co-workers and supervisors tend to experience a high level of job satisfaction [44-46] and low levels of anxiety and depression [47], while being associated with higher levels of personal accomplishment [46]. On the other hand, employees with high perceptions of work demand also scored high in perceived stress at work [45, 48], felt anxious and depressed [49] and tended to be faced with psychological disorders such as obsessive compulsive disorder, paranoid ideation and psychoticism. Not only that, they also have poorer general health [50], and were associated with higher levels of emotional exhaustion and somatic complaints [46]. In addition, De Lange and colleagues [51] claimed that low job control and high demands are related to low affective wellbeing, and high strain. Workers may face work overload when they report having high demands put upon them and having low control. This could mean that workers lack the opportunity to decide how to deal optimally with the demands they face. These situations lead to psychological stress reactions and low affective well-being [51].

Past research has found that well-being can be influenced by various factors, ranging from personal to work-related characteristics. As proposed by Mark and Smith [52] in the Demands, Resources, and Individual Effects (DRIVE) model, both psychosocial workplace stressors and individual difference factors are important in developing one's subjective experiences of stress or well-being, and result in possible health-related outcomes. This model provides a combination of elements from the Demand, Control and Support (DCS) model [53] and the Effort-Reward Imbalance (ERI) model [54], but adds a more crucial element, which is the individual difference factors. The simple DRIVE model proposed that job characteristics, 
particularly work demands (job demands and extrinsic effort), and work resources (job control, social support and rewards), along with individual differences (coping style, attributional style, intrinsic effort, and demographics), influence various health outcomes, such as anxiety, depression, and job satisfaction. This comprehensive model also emphasises flexibility, whereby different organisational and personal variables can be inserted into the framework and tested, either as predictors or outcomes [52].

\subsection{Attitudes toward Training and Well- being}

In the training field, researchers generally examine factors that contribute to the effectiveness of training programs, or what makes the transfer of the knowledge and skills from the training program to the work setting successful. These factors can range from training design, to learner characteristics and the work environment [55-59]. For this study, the learner characteristics chosen were the motivation to learn, learning, transfer intention and cognitive dissonance. For the purpose of this study, these four variables are referred to as attitudes towards training.

Very few studies have so far investigated the associations between these four training attitudes and well-being, particularly in specific contexts (e.g., those related to training). Furthermore, no research, as far as we know, has examined the four attitudes simultaneously. However, some researchers have studied the association between these attitudes on wellbeing separately; for example, the influence of motivation to learn on well-being [60]; and the association between learning and well-being [61]. In addition, very few studies have examined the relationship between transfer intention and cognitive dissonance on well-being.

A few studies have examined the relationship between motivation to learn and well-being [60, 62]. Noe [59] defined motivation to learn as a specific enthusiasm shown by an individual to learn the content of the training program. The assessment of the motivation to learn comprises items that measure an individual's determination for learning and persistence when the program content is difficult and challenging [63]. Research on the influence of motivation to learn on wellbeing has been mostly conducted among students from various backgrounds, such as university [60] and school students [64]. It has been shown that students with high intrinsic motivation tend to score higher in life satisfaction, report more positive affect, obtain better academic attainment [65], have good adjustment [7] and more success in the first quarter of the semester [66]. On the other hand, demotivated or unmotivated students were more prone to experiencing anxiety and depression [65], poor adjustment and low well-being [7]. Moreover, Henning and colleagues [60] found that two domains in learning motivation, namely, selfefficacy and intrinsic value, were positively correlated with four domains of quality of life, namely, physical, psychological, social and environmental. These findings maintain the notion proposed by Ryan and Deci [67], in which intrinsic motivation is one of the determining factors of human well-being.

Learning can also help in boosting individuals' levels of well-being $[61,68,69]$. Learning is defined as the process of acquiring new, or modifying existing, knowledge, skills, or attitudes [70]. It can be divided into learning that is formal - more organised, structured, and having specific learning objectives - and informal -usually occurring outside the structured learning environment [71]. Jenkins and Mostafa [61] contended that the relationship between learning and well-being is significant if the type of learning is informal learning (for example, music, sports clubs or exercise classes), and this significance is due to the intrinsic enjoyment and the way they view these classes as a medium to get together with others. Moreover, through learning, individuals will gain new knowledge and information, hence enhancing their positive feelings and making them feel happier and more empowered [68]. In addition, Perkins and Williamon [72] suggest that adults who join a 10week program of music making could provide subjective experiences of pleasure, such as enjoyment while playing an instrument, increased social interactions by playing the instrument together, musical ambition fulfilment, satisfaction through musical progress, and a feeling of pride and accomplishment in their ability to make music. Not only that, Nikolova and colleagues [69] also examined how learning may act as a buffer in the relationship between task restructuring and well-being. The results revealed that when an employee's level of learning or the acquisition of new skills were low, the association between task restructuring and emotional exhaustion was strong and positive. It can be said that a good understanding of the newly acquired skills helps the employees to be 
well prepared in coping with the demand of learning associated with task restructuring, thus facilitating the process of improving their wellbeing [69].

Moving on to the association between transfer intention and well-being, transfer intention originated from the idea of implementation intention that was proposed by Gollwitzer [73]. Gollwitzer [73] proposed that one could successfully achieve one's goal if one made an if-then plan, specifying when, where, and how one could instigate responses that promoted goal realisation (e.g., 'If I encounter situation $X$, then I will perform response $Y^{\prime}$ ). Research on transfer intentions or implementation intentions in the psychology-related field were mostly on intervention, which applied implementation intention as a behavioural intervention in promoting desirable behaviours. For example, to improve sleep behaviour [74], to increase exercise behaviour and physical activity $[75,76]$ and to reduce unhealthy eating [77] and drinking behaviour [78]. Very few studies have investigated the influence of implementation intention, behavioural intention or transfer intention in the context of training on individuals' level of well-being. One of the studies that examined the association between intention and well-being was that of Pasikowski, Sek, and Ziarko [79], where they explained intention completeness using the four characteristics that consist of the agent of an action, action plan, involvement in goal realisation and the information on temporal and spatial context of implementing an intention. The authors found that well-being could be predicted by intention completeness, particularly when individuals specify the place and time to implement the behaviour, and was the strongest predictor among other variables. They concluded that the strength of the intention (characterised from weak to strong intention to implement or continue health behaviours, intention completeness and action orientation in health behaviour planning) are the main health behaviour predictors. In addition, Hattar, Pal [80] claimed that the stronger the intention to perform a certain behaviour, for example, physical activity, with a very specific plan on how to do it, the more likely it is that individuals will experience low negative psychological outcome and become physically healthier, through physical behaviour. This result is consistent with Lyubomirsky, Sheldon [81], who demonstrated that certain types of intentional behaviour or activity could influence individuals' level of well-being, such as intention to exercise, eat healthy food or use better coping strategies. In summary, it was apparent that individuals could intentionally change their level of well-being or happiness and increase their health behaviour through intentional behaviour, implementation intention or intended behaviour [81].

The investigation of the role of cognitive dissonance on training effectiveness or transfer of training is still relatively limited, as is its association with well-being. Cognitive dissonance is defined as being when a person holds two or more cognitions that are contradictory to each other, or dissonant, and results in an unpleasant state of emotion that can lead to cognition alteration [82]. Weisweiler and colleagues [83] provided new insight and suggested that individuals fail to transfer their newly acquired knowledge and skills to the workplace because they might encounter cognitive inconsistency or cognitive dissonance. Cognitive dissonance starts with cognitive inconsistency or discrepancy, and then the feeling of dissonance begins, where an individual experiences uncomfortable negative affective states. An individual then feels motivated to reduce this dissonance, and tries to adjust their cognitions or behaviour to reduce their cognitive inconsistency [82]. Furthermore, it was found that individuals who experience high cognitive dissonance reported feeling stressed, and having poorer physical and mental health [84]. In addition, a positive relationship between cognitive dissonance and anxiety can also be found [85], where the presence of dissonance was considered to be associated with feelings of anxiety. Suinn [85] suggests that when individuals experience arousal from cognitive inconsistency, two types of motivation may occur: first, motivation may increase as a desire to reduce dissonance, as proposed by Festinger [86]; or second, motivation might increase by the desire to reduce anxiety.

The influence of motivation to learn [60,62] and learning $[61,68,72]$ on well-being is established. However, the role of transfer intention and cognitive dissonance on well-being are still underexplored. Hence, this study examines the influence of motivation to learn and learning, along with transfer intention and cognitive dissonance on individual levels of well-being. Thus, this study was the first to investigate these four attitudes simultaneously and most importantly, within the context of training programs. The findings from this study will 
benefit both the training and well-being research fields, considering that training effectiveness predictors - called 'attitudes to training' in this study - might play an important role in determining one's level of well-being.

In addition, as mentioned above, even though the DRIVE model [52] is a comprehensive model that takes into account various work demands and resources, and the role of individual difference factors in determining the stress or well-being and health-related outcomes of the workers, more specific attitudes, especially attitudes to training, were not included. Building from this imperfection and the flexibility of the model, into which any organisational and personal variables could be entered, this current study applied the key elements of the model, particularly the job characteristics and individual differences, along with introducing the influence of attitudes to training on workers' wellbeing.

As shown in Fig. 1, it was predicted that workers with high motivation to learn the content of the training programs would perceive that their understanding of the knowledge and skills presented in the training programs was improved, and would exhibit high intention to implement the new knowledge and skills in the work setting, and would also experience positive well-being. Meanwhile, those who encountered cognitive inconsistency when applying the new knowledge and skills, would also experience negative well-being; however, examination of the association between attitudes to training and well-being need to be controlled for other variables, particularly demographics and various psychosocial characteristics.

\subsection{Aim and objective}

The main aim of this study was to investigate the role of attitudes toward training that consist of motivation to learn, learning, transfer intention and cognitive dissonance on individuals' level of well-being. Since well-being could be influenced by various factors, demographic variables and psychosocial characteristics were controlled. Hence, the main hypothesis was:

H1: Training attitudes influence well-being after controlling for demographics and psychosocial characteristics.

\section{METHODS}

\subsection{Participants}

The study was carried out with the approval of the Ethics Committee, School of Psychology, Cardiff University, and with the informed consent of the participants.

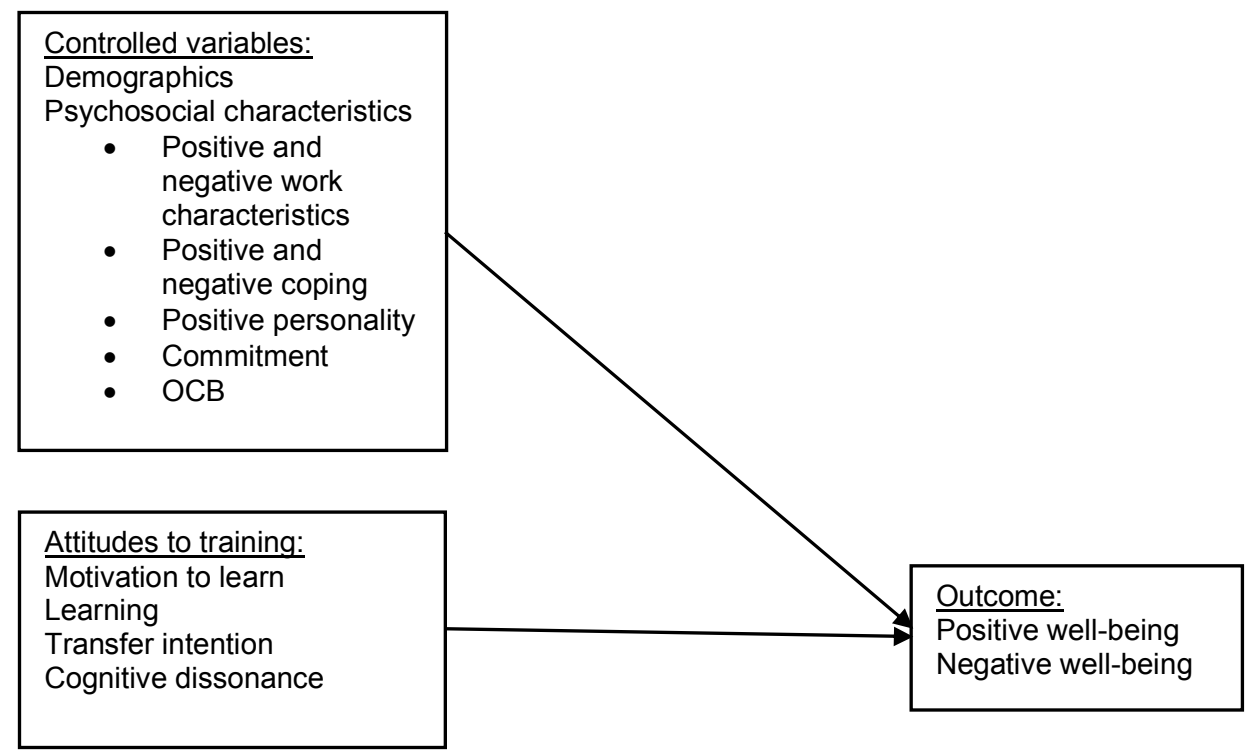

Fig. 1. The conceptual framework 
A total of 210 volunteers from the Qualtrics research panel completed an online survey that was cross-sectional in nature. Participant recruitment involved purposive sampling. The main inclusion criterion was that participants must be employed full-time and attend training courses at work related either to human resources, health and safety or specific skills. Among the respondents, 94 of them attended skills training, 92 attended health and safety training and the rest (24) attended human resources courses.

The majority of respondents were 31 to 40 years old $(66,31.4 \%)$, and were married $(88,41.9 \%)$. Regarding education, over a quarter held an undergraduate degree $(58,27.6 \%)$ and the majority were of white ethnicity $(179,85.2 \%)$. For the training questions, over a third of respondents attended training courses that had an average duration of one day $(80,38.1 \%)$, and nearly all reported that the training was related to their work (194, 92.4\%). Just under half found that it was also very useful $(85,40.5 \%)$.

\subsection{Materials}

This study used single-item measures because they have advantages over multiple-item measures: first, they are economically more favourable. As Burisch [87] noted, the process of measuring multiple items consumes significant funds and manpower [88]. Second, single items help reduce nonresponse rates [89]. Participants tend not to provide honest answers and sometimes do not provide any response at all. Hence, most of the variables in this study used single items and brief measures.

Psychosocial characteristics and well-being were assessed using the Short-Swell scale [90]. Nine items from this scale were used, comprising negative and positive work characteristics, positive and negative coping, positive personality, OCB, commitment and positive and negative well-being. Work characteristics assessed the participants' job demands, effort, control, support, and reward that they experienced at work. Meanwhile, coping strategies measured how they dealt with problems, either positively (e.g., focus on the problem or get social support) or negatively (e.g., avoid it, blaming themselves or using wishful thinking). Next, positive personality assessed the participants' overall level of self-esteem, selfefficacy and optimism. Regarding the OCB item, this measured the participants' behaviours, such as being helpful and courteous to, and a good sport with, other people in the workplace. Next, commitment to organisation assessed whether the participants had high job satisfaction, and whether they were motivated employees that did not wish to quit their job. Lastly, well-being items measured the participants' level of life satisfaction, happiness, stress, anxiety, and depression. All items had a response scale of 1 (Not at all) to 10 (Very much so).

Training attitudes consist of motivation to learn, learning, transfer intention and cognitive dissonance. All of the items for these variables used other researchers' work as a guideline and modified the statement in accordance with the research objectives and to ensure that it was more suitable for the sample. Motivation to learn has four items that originate from the Motivated Strategies for Learning Questionnaire [91]. This construct assessed participant eagerness to learn the content of the training programs. The reliability of this construct was found to be 0.931 . Meanwhile, learning and transfer intention have three and two items, respectively. For learning construct, it measured participant perception regarding their knowledge that was improved after attending the training, while the transfer intention construct assessed respondents' intention in implementing the new knowledge and skills into the work setting. These two variables were derived from Machin and Fogarty [92] work, as a guideline. The reliabilities of learning and transfer intention were 0.922 and 0.872 , respectively. Finally, cognitive dissonance has two items that originated from a study by Levin, Harriott [93]. This construct assessed participants' uncomfortable negative affective state whenever they used the newly acquired knowledge and skills, with the reliability for these items being determined to be 0.906. The response scale for all training attitudes items ranged from 1 (Strongly disagree) to 10 (Strongly agree). All of the training attitude constructs have a good divergent and convergent validity. When factor analysis was conducted for all four constructs, there was a two-factor solution with positive attitudes in the first factor (motivation to learn, learning and transfer intention) and negative attitudes in the second factor (cognitive dissonance). In addition, correlational analysis (Table 2) showed that all of the positive attitudes were highly correlated with each other, ranging from .796 to .893 , while the negative attitudes had a weak, yet significant, correlation with the positive attitudes $(r=.175)$. 
The list of questions in the survey and frequencies (\%) in response categories are shown in the Appendix (Table 1).

\subsection{Data analysis}

The data were analysed using IBM SPSS 20 (Statistical Package for Social Sciences). Pearson's correlation coefficients were used to study the relationship between psychosocial characteristics, training attitudes and well-being. In addition, to examine the influence of training attitudes on well-being after controlling for other variables (demographic and psychosocial characteristics), hierarchical regression was employed.

\section{RESULTS}

The aim of this study was to investigate the role of training attitudes on well-being, after controlling for other variables (demographics and psychosocial characteristics). Before presenting the results related to the main objective, as a summary, Table 1 reveals that almost all of the positive psychosocial characteristics show a significant positive relationship with motivation to learn, learning, transfer intention and positive well-being. All of them were greater or equal to $r(208)=.27, p<.01$, two-tailed. Meanwhile, all of the negative psychosocial characteristics show a statistically significant correlation with cognitive dissonance and negative well-being. The relationships are greater or equal to $r(208)=.43$, $p<.01$.

Table 2 also demonstrates that motivation to learn, learning and transfer intention were significantly correlated (moderate) with positive well-being and were greater or equal to $r(208)=$ $.35, p<.01$, while cognitive dissonance positively associated (moderate) with negative well-being, $r(208)=.48, p<.01$.

Moving on to the main objective, Table 3 illustrates the hierarchical regression analysis where demographic variables (Model I) and psychosocial characteristics (Model II) were regarded as the control variables, positive and negative well-being as the dependent variables, and attitudes toward training (Model II) as the input. Regarding positive well-being as the dependent variable, Model 1, with age, gender and education as the predictors, explained $0.02 \%$ of the variance and was not significant $(F(3,205)=.868, p>.459)$. Model 2 , in which seven psychosocial characteristics were added, explained significantly more variance ( $R^{2}$ change $=.527, F(7,198)=32.397, p<.000)$. The model explains $52 \%$ of the variance in positive wellbeing (Adjusted $R^{2}=.516$ ). Model 3, in which four training attitudes were added, explained a slight increase of variance but this increase was not significant $\left(R^{2}\right.$ change $=.004, F(4,194)=$ $.432, p>$.785). Model 3 explained $51 \%$ of the variance in positive well-being (Adjusted $R^{2}=$ $.511)$ and was significant $(F(14,194)=16.517, p$ $<.000)$. The significant predictors in Model 3 were positive personality and commitment.

In Table 4, in which negative well-being is the dependent variable, Model 1, with demographic information as the predictors, explained $5.7 \%$ of the variance and was significant $(F(3,205)=$ $4.142, p<.007)$. Model 2 , in which psychosocial characteristics were added, explained significantly more variance $\left(R^{2}\right.$ change $=.309$, $F(7,198)=13.758, \mathrm{p}<.000)$. The model explains $33 \%$ of the variance in negative wellbeing (Adjusted $R^{2}=.334$ ). Model 3, in which training attitudes were added, explained slightly more variance but this increase was not significant $\left(R^{2}\right.$ change $=.029, F(4,194)=2.348$, $p>$.056). Model 3 explained $35 \%$ of the variance in negative well-being (Adjusted $R^{2}=.351$ ) and was significant $(F(14,194)=9.046, \mathrm{p}<.000)$. The significant predictors in Model 3 were negative work characteristics, coping, personality, and cognitive dissonance.

As a summary, after controlling for demographics and psychosocial characteristics, only cognitive dissonance predicts negative well-being, while motivation to learn, learning, and transfer intention did not predict either positive or negative well-being.

\section{DISCUSSION}

The main objective of this study was to examine the link between attitudes toward training on positive and negative well-being among workers after controlling for other variables. The control variables were age, gender, education and psychosocial characteristics. It was important to control these variables because well-being can be influenced by various factors. Hence, to investigate the impact of attitudes towards training on individuals' level of well-being, these other variables need to be controlled for.

It was determined that motivation to learn, learning and transfer intention were positively correlated with positive well-being, while 
cognitive dissonance was associated with negative well-being. These results suggest that workers that evaluate themselves as highly motivated to learn the content of the training programs understand such content better after attending them; they have high intention to implement the newly acquired knowledge and skills to the work setting; further, they also perceived themselves as happier, more satisfied in life and always in a positive mood.

The positive association between motivation to learn and well-being is consistent with the findings of Burton and colleagues [94], and Bailey and Phillips [65], who found that individuals with high intrinsic motivation were reported to have greater levels of well-being. According to the self-determination theory, individuals who possess high motivation, where they are curious to learn, as well as to explore new knowledge and skills, and who find the learning process a pleasant experience, have higher life satisfaction, are happier and have a greater sense of well-being [95]. Not only that, learning can also help enhance individuals' levels of well-being due to feeling empowered and confident as a result of the newly acquired knowledge [96,97]. The positive relationship between intention and well-being is also consistent with what has been proposed by Pasikowski, Sek, and Ziarko [79] and Shim, Serido, and Tang [98]. Individuals who have high behavioural intention will experience positive well-being, as suggested by Shim, Serido, and Tang [98], whereby an individual can intentionally increase their level of happiness through intentional behaviour.

The associations between training attitudes and positive well-being were however no longer significant when established predictors were controlled for. This result suggests that earlier results attributed to training attitudes may reflect other factors and that personality and commitment are stronger predictors than motivation to learn, learning and transfer intention. Some prior studies that have noted the importance of personality on one's level of wellbeing include Strickhouser, Zell and Krizan [99] and Howell and colleagues [100]. The former authors found that all of the Big Five personality factors as a whole had a moderate to large effect on health and well-being, particularly with respect to health behaviour and mental health. Meanwhile in this study, those with a positive personality and who were characterised as having a high level of extraversion, agreeableness, conscientiousness, openness to experience, and low neuroticism, along with high self-esteem, self-efficacy and optimism, tended to have a high level of well-being. Some authors have speculated that when individuals' have high positive personality they will experience frequent positive emotions because this personality helps them to achieve their relatedness and personal competence needs [100]. Meanwhile Lui et. al. [16] suggest that being socialised with other people tends to shape their optimistic expectancies, and help in activating the application of approach-oriented coping behaviours, which in turn elevates their wellbeing level. In addition, due to having a positive personality, they were more socially connected to the society, which led them to be more satisfied with their life and therefore they were happier [19].

The current study also found that commitment is a strong predictor in determining individual level of well-being. This result suggests that those with high organisational commitment tend to experience more positive moods and are happier and highly satisfied with their life. This finding further supports the proposal of Meyer and Maltin [101], who gathered evidence regarding the importance of organisational commitment on employees' level of well-being. Affective commitment could predict general health [102], positive affect [103], physical well-being [104], life satisfaction [105] and many more factors. As suggested by Glazer and Kruse [37], a possible explanation for this phenomenon may be the buffering effects of commitment on stressorstrain relations. According to the authors, workers with high affective commitment to the organisation are less likely to experience stress in the workplace, or they are more likely to receive greater access to resources [37]. Commitment seems to provide a meaningful relationship between employees and the organisation, hence employee might better accept the anxiety caused by workplace stressors.

Moving on to the result regarding the influence of cognitive dissonance in the context of training on well-being, it was found that cognitive dissonance predicts ones' level of negative wellbeing. This finding suggests that workers who experience cognitive inconsistency, which is characterised as feeling uncomfortable when using new knowledge or skills and feeling conflicted or confused regarding whether or not to use the newly acquired knowledge and skills in 
Table 2. Correlation analysis between psychosocial characteristics, training attitudes and well-being

\begin{tabular}{|c|c|c|c|c|c|c|c|c|c|c|c|c|}
\hline Variables & (1) & $(2)$ & (3) & $(4)$ & (5) & (6) & $(7)$ & $(8)$ & (9) & (10) & (11) & (12) \\
\hline Neg. work characteristics (1) & 1 & & & & & & & & & & & \\
\hline Pos. work characteristics (2) & .030 & 1 & & & & & & & & & & \\
\hline Positive coping (3) & $.179^{* *}$ & $.425^{\star *}$ & 1 & & & & & & & & & \\
\hline Negative coping (4) & $.414^{\star *}$ & $.176^{*}$ & -.049 & 1 & & & & & & & & \\
\hline Positive personality (5) & $.200 * *$ & $.316^{\star *}$ & $.563^{* *}$ & .005 & 1 & & & & & & & \\
\hline OCB (6) & $.146^{\star}$ & $.379^{* *}$ & $.438^{* *}$ & .067 & $.442^{* *}$ & 1 & & & & & & \\
\hline Commitment (7) & .051 & $.532^{\star *}$ & .448 & .088 & $.437^{* *}$ & $.460^{* *}$ & 1 & & & & & \\
\hline Motivation to learn (8) & -.078 & $.268^{* *}$ & $.354^{* *}$ & -.033 & $.405^{\star \star}$ & $.400^{* *}$ & $.418^{* *}$ & 1 & & & & \\
\hline Learning (9) & -.016 & $.290^{\star *}$ & $.283^{\star *}$ & .013 & $.413^{\star *}$ & $.391^{* *}$ & $.484^{\star \star}$ & $.893^{* *}$ & 1 & & & \\
\hline Transfer intention (10) & .044 & $.349^{\star \star}$ & .310 & .076 & $.379^{\star *}$ & $.330^{* *}$ & $.489^{* *}$ & $.796^{\star *}$ & $.802^{\star *}$ & 1 & & \\
\hline Cognitive dissonance (11) & $.431^{* *}$ & .093 & -.042 & $.578^{* *}$ & .110 & .005 & .097 & .069 & .118 & $.175^{*}$ & 1 & \\
\hline Positive well-being (12) & .126 & $.388^{* *}$ & $.464^{\star *}$ & .014 & $.693^{\star *}$ & $.397^{* *}$ & $.501^{\star \star}$ & $.360^{* *}$ & $.386^{* *}$ & $.350 * *$ & .102 & 1 \\
\hline Negative well-being (13) & $.402^{\star \star}$ & .112 & .055 & $.505^{\star *}$ & -.057 & -.040 & .097 & -.076 & -.026 & .033 & $.476^{\star *}$ & $-.184^{\star *}$ \\
\hline
\end{tabular}


Table 3. Hierarchical multiple regression for positive well-being

\begin{tabular}{|c|c|c|c|c|c|c|c|c|c|}
\hline \multirow{3}{*}{$\begin{array}{l}\text { Dependent variable } \\
\text { Independent } \\
\text { variable } \\
\text { Control variable } \\
\end{array}$} & \multicolumn{9}{|c|}{ Positive well-being } \\
\hline & \multicolumn{3}{|c|}{ Model I } & \multicolumn{3}{|c|}{ Model II } & \multicolumn{3}{|c|}{ Model III } \\
\hline & $\boldsymbol{\beta}$ & $t$ & $p$ & $\beta$ & $\mathbf{t}$ & $\mathbf{p}$ & $\beta$ & $\mathbf{t}$ & $\mathbf{p}$ \\
\hline Age & -.016 & -.224 & .823 & .060 & 1.113 & .267 & .074 & 1.333 & .184 \\
\hline Gender & .096 & 1.376 & .170 & .065 & 1.322 & .188 & .073 & 1.446 & .150 \\
\hline Education & .046 & .663 & .508 & .005 & .090 & .928 & .003 & .064 & .949 \\
\hline $\begin{array}{l}\text { Neg. work } \\
\text { characteristics }\end{array}$ & & & & .001 & .023 & .981 & -.013 & -.216 & .829 \\
\hline $\begin{array}{l}\text { Pos. work } \\
\text { characteristics }\end{array}$ & & & & .109 & 1.755 & .081 & .114 & 1.799 & .074 \\
\hline Positive coping & & & & -.022 & -.322 & .748 & -.008 & -.120 & .905 \\
\hline Negative coping & & & & -.010 & -.180 & .857 & -.030 & -.464 & .643 \\
\hline Positive personality & & & & .579 & 9.148 & .000 & .567 & 8.684 & .000 \\
\hline OCB & & & & .015 & .255 & .799 & .014 & .226 & .822 \\
\hline Commitment & & & & .195 & 3.099 & .002 & .183 & 2.712 & .007 \\
\hline Predictors & & & & & & & & & \\
\hline Motivation to learn & & & & & & & -.041 & -.334 & .739 \\
\hline Learning & & & & & & & .108 & .887 & .376 \\
\hline Transfer intention & & & & & & & -.056 & -.619 & .537 \\
\hline $\begin{array}{l}\text { Cognitive } \\
\text { dissonance }\end{array}$ & & & & & & & .056 & .875 & .383 \\
\hline $\mathrm{R}^{2}$ & & .013 & & & .540 & & & .544 & \\
\hline$\Delta \mathrm{R}^{2}$ & & -.002 & & & .516 & & & .511 & \\
\hline $\mathrm{F}$ change & & .868 & & & 32.397 & & & .432 & \\
\hline Sig. F change & & .459 & & & .000 & & & .785 & \\
\hline
\end{tabular}

Table 4. Hierarchical multiple regression for negative well-being

\begin{tabular}{|c|c|c|c|c|c|c|c|c|c|}
\hline \multirow{3}{*}{$\begin{array}{l}\text { Dependent variable } \\
\text { Independent } \\
\text { variable } \\
\text { Control variable } \\
\end{array}$} & \multicolumn{9}{|c|}{ Negative well-being } \\
\hline & \multicolumn{3}{|c|}{ Model I } & \multicolumn{3}{|c|}{ Model II } & \multicolumn{3}{|c|}{ Model III } \\
\hline & $\beta$ & $\mathbf{t}$ & $p$ & $\beta$ & $\mathbf{t}$ & $p$ & $\beta$ & $\mathbf{t}$ & $p$ \\
\hline Age & -.177 & -2.564 & .011 & -.123 & -1.935 & .054 & -.103 & -1.623 & .106 \\
\hline Gender & -.148 & -2.171 & .031 & -.130 & -2.238 & .026 & -.110 & -1.901 & .059 \\
\hline Education & .084 & 1.223 & .223 & .045 & .764 & .446 & .036 & 619 & .537 \\
\hline $\begin{array}{l}\text { Neg. work } \\
\text { characteristics }\end{array}$ & & & & .281 & 4.286 & .000 & .215 & 3.074 & .002 \\
\hline $\begin{array}{l}\text { Pos. work } \\
\text { characteristics }\end{array}$ & & & & .007 & .091 & .928 & .006 & .079 & .937 \\
\hline Positive coping & & & & .177 & 2.254 & .025 & .206 & 2.578 & .011 \\
\hline Negative coping & & & & .345 & 5.097 & .000 & .249 & 3.355 & .001 \\
\hline Positive personality & & & & -.215 & -2.897 & .004 & -.234 & -3.115 & .002 \\
\hline OCB & & & & -.142 & -2.067 & .040 & -.110 & -1.556 & .121 \\
\hline Commitment & & & & .116 & 1.568 & .118 & .104 & 1.335 & .183 \\
\hline Predictors & & & & & & & & & \\
\hline Motivation to learn & & & & & & & -.052 & -.367 & .714 \\
\hline Learning & & & & & & & .008 & .055 & .956 \\
\hline Transfer intention & & & & & & & .006 & .062 & .950 \\
\hline Cognitive dissonance & & & & & & & .226 & 3.046 & .003 \\
\hline & & .057 & & & .366 & & & .395 & \\
\hline$\Delta \mathrm{R}^{2}$ & & .043 & & & .334 & & & .351 & \\
\hline $\mathrm{F}$ change & & 4.142 & & & 13.758 & & & 2.348 & \\
\hline Sig. F change & & .007 & & & .000 & & & .056 & \\
\hline
\end{tabular}


the work setting, tend to perceive themselves as having more stress, and being anxious and depressed. This finding appears to be robust in that even though there were significant correlations between attitudes towards training and well-being, after controlling for other variables, only cognitive dissonance significantly impacted negative well-being. As proposed by Festinger [86], cognitive dissonance theory explains the four-step process of dissonance arousal and reduction, that starts with cognitive inconsistency or discrepancy; second is the feeling of dissonance where an individual feels an uncomfortable negative affective state; third, an individual feels motivation to reduce dissonance; and finally, discrepancy reduction where an individual adjusts their cognition or behaviour to reduce cognitive inconsistency. For example, in this study, cognitive dissonance occurs when an individual learns something new in the training program that contradicts with their prior knowledge or routine. If an individual is firmly committed to that prior particular knowledge or routine, they most likely will end up refusing the new knowledge that requires them to dispose of their existent knowledge in order to reduce feelings of dissonance [106]. Individuals that experience high cognitive dissonance are reported to feel stressed, and this finding is consistent with that of Palsane [84]. Uncomfortable negative affective states, or dissonance caused by two or more cognitive conflicts, will lead to feelings of discomfort, arousal and restlessness [86], hence increasing individuals' levels of stress. This study highlighted the influence of cognitive dissonance in the context of training on individuals' level of negative well-being.

\subsection{Implications, limitations and future directions}

This study has several implications, including contribution to the existing body of knowledge, and also in the creation of new knowledge, along with a more practical use. Because this study is the first to combine several training attitudes simultaneously and most importantly within the context of training, into a well-being research context, the findings from this study thus contribute to new knowledge. In this study, training attitudes consisting of the motivation to learn, learning, transfer intention and cognitive dissonance in the context of training were selected to explore the influence of these variables on well-being. Past studies in the training field have found that these variables are useful in predicting training effectiveness and transfer of training [55,107-109]. The main objective of this study was to examine whether these training attitudes could also predict wellbeing, with the results revealing that all of these variables have an association with well-being, and cognitive dissonance could predict ones' level of well-being. The combination of both training and well-being research fields in this study provide new knowledge and perspectives, where researchers in training fields should also consider adding well-being into their research, even though the training programs are not aimed at enhancing trainees' well-being and focus on improving job-related skills.

These findings will therefore be of practical use among training practitioners or to others who may find this relevant and beneficial to them. As an example, because it was found that cognitive dissonance could influence well-being; trainers could encouraged the trainees to be more confident in applying the new knowledge and skills into the work setting and convince them that such new knowledge and skills are better than their previous knowledge and skills before they attended training. This approach could not only increase the transferability of the training or allow training programs to be more successful, but may also be beneficial to trainees, where the enrichment of well-being could still be achieved, even though the programs were not aimed to increase their level of well-being.

This study does, however, have a number of limitations. First, its results cannot be generalised because participant selection was purposive and involved convenience sampling; it is not random and stratified and only focused on certain criteria, which were aimed at workers who have experience in attending training programs only. Second, this study examined four attitudes in the context of broad training programs. The participants had undergone various types of programs or courses, such as those related to human resources; hence, a clear distinction cannot be made as to which of the courses actually helped improve students' well-being. Their attitudes toward certain programs or courses may differ and might also bring different influences to well-being levels. Lastly, the study used a cross-sectional method, hence no cause and effect relationships can be suggested between training attitudes and well-being.

There are a few improvements that could be made to this study. First, since the study 
examined attitudes to training in a broader context, future research could focus on more specific programs or courses and investigate whether the specific content of the programs or courses might produce different levels of attitudes, hence influencing to varying degrees individual well-being levels. Second, a longitudinal approach, preferably with an intervention, could improve the study by not only examining well-being changes over time, but also determining the causal effect of the relationship between training attitudes and well-being.

\section{CONCLUSION}

Training is important for developing and enhancing one's expertise to meet current and future job demands and continue personal development. At the same time, well-being needs to remain positive and high to ensure that they can perform well in their job and become more productive, and to prevent any mental health issues. Results of this study have shown that positive training attitudes comprising motivation to learn, learning and transfer intention have a relationship with well-being. However, these associations were no longer significant when personality and commitment were controlled for. Meanwhile, cognitive dissonance, which is characterised as having uncomfortable feelings when using newly acquired knowledge and skills, predicts negative well-being among workers and this remained significant even when established predictors were controlled for.

\section{COMPETING INTERESTS}

Authors have declared that no competing interests exist.

\section{REFERENCES}

1. Werner JM, DeSimone RL. Human resource development. Cengage Learning; 2011.

2. Kahneman D, Diener E, Schwarz N. Wellbeing: Foundations of hedonic psychology. Russell Sage Foundation; 1999.

3. Ryff CD, Singer B. Psychological wellbeing: Meaning, measurement, and implications for psychotherapy research. Psychotherapy and Psychosomatics. 1996; 65(1):14-23.

4. Albrecht SL. The influence of job, team and organizational level resources on employee well-being, engagement, commitment and extra-role performance
Test of a model. International Journal of Manpower. 2012;33(7):840-853.

5. Anglim J, Grant S. Predicting psychological and subjective well-being from personality: Incremental prediction from 30 facets over the Big 5. Journal of Happiness Studies. 2016;17(1):59-80.

6. Arenas $A$, et al. Workplace bullying in a sample of Italian and Spanish employees and its relationship with job satisfaction, and psychological well-being. Frontiers in Psychology. 2015;6.

7. Baker SR. Intrinsic, extrinsic, and amotivational orientations: Their role in university adjustment, stress, well-being, and subsequent academic performance. Current Psychology. 2004;23(3):189202.

8. Bietry F, Creusier J. Well-being at work: Contributions of a person-centred study. Relations Industrielles-Industrial Relations. 2015;70(1):11-35.

9. Birditt KS, Nevitt MR, Almeida DM. Daily interpersonal coping strategies: Implications for self-reported well-being and cortisol. Journal of Social and Personal Relationships. 2015;32(5):687706.

10. Brunetto $\mathrm{Y}$, et al. Emotional intelligence, job satisfaction, well-being and engagement: Explaining organisational commitment and turnover intentions in policing. Human Resource Management Journal. 2012;22(4):428-441.

11. Conley JJ. Longitudinal stability of personality traits: A multitrait-multimethodmultioccasion analysis. Journal of Personality and Social Psychology. 1985; 49(5):1266.

12. Corr PJ, Matthews G. The Cambridge handbook of personality psychology. Cambridge University Press Cambridge; 2009.

13. Zhai Q, et al. Big Five personality traits, job satisfaction and subjective wellbeing in China. International Journal of Psychology. 2013;48(6):1099-1108.

14. Plopa M, Plopa W, Skuzińska A. Bullying at work, personality and subjective wellbeing. Journal of Occupational Health Psychology. 2017;22(1):19.

15. Burns RA, Machin MA. Identifying gender differences in the independent effects of personality and psychological well-being on two broad affect components of subjective well-being. Personality and Individual Differences. 2010;48(1):22-27. 
16. Lui PP, et al. Big 5 personality and subjective well-being in Asian Americans: Testing optimism and pessimism as mediators. Asian American Journal of Psychology. 2016;7(4):274.

17. Hudson NW, Fraley RC. Changing for the better? Longitudinal associations between volitional personality change and psychological well-being. Personality and Social Psychology Bulletin. 2016;42(5): 603-615.

18. Cheng $\mathrm{C}$, et al. Explaining differences in subjective well-being across 33 nations using multilevel models: Universal personality, cultural relativity, and national income. Journal of Personality. 2016;84(1): 46-58.

19. Harris K, et al. Why are Extraverts more satisfied? personality, social experiences, and subjective well-being in college. European Journal of Personality. 2017; 31(2):170-186.

20. Bryant $\mathrm{C}$, et al. Antecedents of attitudes to aging: A study of the roles of personality and well-being. The Gerontologist. 2016; 56(2):256-265.

21. Henning $G$, et al. The role of personality for subjective well-being in the retirement transition-Comparing variable-and personoriented models. Personality and Individual Differences. 2017;116:385392.

22. Tanksale D. Big Five personality traits: Are they really important for the subjective well-being of Indians? International Journal of Psychology. 2015;50(1):64-69.

23. Wilt JA, et al. Personality, religious and spiritual struggles, and well-being. Psychology of Religion and Spirituality. 2016;8(4):341.

24. Halama $\mathrm{P}$, Martos $\mathrm{T}$, Adamovova $\mathrm{L}$. Religiosity and well-being in Slovak and Hungarian student samples: The role of personality traits. Studia Psychologica. 2010;52(2):101.

25. Augusto Landa JM, Martos MP, LopezZafra E. Emotional intelligence and personality traits as predictors of psychological well-being in Spanish undergraduates. Social Behavior and Personality: An International Journal. 2010; 38(6):783-793.

26. Arshad S, Rafique R. Personality and creativity as predictors of psychological well-being in college students. Pakistan Journal of Psychological Research. 2016; 31(1):139.
27. Liu WL, et al. Core self-evaluations and coping styles as mediators between social support and well-being. Personality and Individual Differences. 2016;88:35-39.

28. Lazarus RS, Folkman S. Stress, appraisal and coping. New York: Springer; 1984.

29. Gloria AM, Castellanos J, Orozco V. Perceived educational barriers, cultural fit, coping responses, and psychological wellbeing of Latina undergraduates. Hispanic Journal of Behavioral Sciences. 2005; 27(2):161-183.

30. Freire $\mathrm{C}$, et al. Profiles of psychological well-being and coping strategies among university students. Frontiers in Psychology. 2016;7.

31. Mosley Jr TH, et al. Stress, coping, and well-being among third-year medical students. Academic Medicine. 1994;69(9): 765-7.

32. Carnicer JG, Calderón C. Empathy and coping strategies as predictors of wellbeing in Spanish university students. Electronic Journal of Research in Educational Psychology. 2014;12(1):129146.

33. Drake KL. Psychology graduate student well-being: The relationship between stress, coping, and health outcomes. University of Cincinnati; 2010.

34. Mowday RT, Steers RM, Porter LW. The measurement of organizational commitment. Journal of Vocational Behavior. 1979;14(2):224-247.

35. Brunetto $\mathrm{Y}$, Farr-Wharton $\mathrm{R}$, Shacklock K. Communication, training, well-being, and commitment across nurse generations. Nursing Outlook. 2012;60(1):7-15.

36. Meyer JP, Allen NJ. A three-component conceptualization of organizational commitment. Human Resource Management Review. 1991;1(1):61-89.

37. Glazer S, Kruse B. The role of organizational commitment in occupational stress models. International Journal of Stress Management. 2008;15(4):329.

38. Organ DW. OCB: The good soldier syndrome. Lexington, MA: Lexington Books; 1988.

39. Boyd NM, Nowell B. Testing a theory of sense of community and community responsibility in non-profit organizations. in Academy of Management Proceedings. Academy of Management; 2014.

40. Bolino MC, Turnley WH, Niehoff BP. The other side of the story: Reexamining prevailing assumptions about 
organizational citizenship behavior. Human Resource Management Review. 2004; 14(2):229-246.

41. Bolino MC, Turnley $\mathrm{WH}$. The personal costs of citizenship behavior: The relationship between individual initiative and role overload, job stress, and workfamily conflict. Journal of Applied Psychology. 2005;90(4):740.

42. Bolino $\mathrm{MC}$, et al. Exploring the dark side of organizational citizenship behavior. Journal of Organizational Behavior. 2013;34(4): 542-559.

43. Loher BT, et al. A meta-analysis of the relation of job characteristics to job satisfaction. Journal of Applied Psychology. 1985;70(2):280.

44. Rydstedt LW, Ferrie J, Head J. Is there support for curvilinear relationships between psychosocial work characteristics and mental well-being? Cross-sectional and long-term data from the Whitehall II study. Work \& Stress. 2006;20(1):6-20.

45. Smith $A$, Smith $H$. An international survey of the wellbeing of employees in the business process outsourcing industry. Psychology. 2016;8(01):160.

46. Pisanti $R$, et al. Occupational coping selfefficacy explains distress and well-being in nurses beyond psychosocial job characteristics. Frontiers in Psychology. 2015;6:1143.

47. Mark G, Smith AP. Occupational stress, job characteristics, coping, and the mental health of nurses. British Journal of Health Psychology. 2012;17(3):505-521.

48. Calnan $M$, et al. Job strain, effort-reward imbalance, and stress at work: Competing or complementary models? Scandinavian Journal of Public Health. 2004;32(2):84-93.

49. Mark G, Smith AP. Effects of occupational stress, job characteristics, coping, and attributional style on the mental health and job satisfaction of university employees. Anxiety, Stress \& Coping. 2012;25(1):6378.

50. Capasso R, Zurlo MC, Smith AP. Ethnicity, work-related stress and subjective reports of health by migrant workers: A multidimensional model. Ethnicity \& Health. 2018;23(2):174-193.

51. De Lange $A H$, et al. "The very best of the millennium": Longitudinal research and the demand-control-(support) model. Journal of Occupational Health Psychology. 2003; 8(4):282.
52. Mark GM, Smith AP. Stress models: A review and suggested new direction. Occupational Health Psychology. 2008;3: 111-144.

53. Karasek Jr RA. Job demands, job decision latitude, and mental strain: Implications for job redesign. Administrative Science Quarterly. 1979:285-308.

54. Siegrist J. Adverse health effects of higheffort/low-reward conditions. Journal of Occupational Health Psychology. 1996. 1(1):27.

55. Burke LA, Hutchins HM. Training transfer: An integrative literature review. Human Resource Development Review. 2007;6(3): 263-296.

56. Baldwin TT, Ford JK, Blume BD. Transfer of training 1988-2008: An updated review and agenda for future research. International Review of Industrial and Organizational Psychology. 2009;24(1): 41-70.

57. Baldwin TT, Ford JK. Transfer of training: A review and directions for future research. Personnel Psychology. 1988;41(1):63-105.

58. Colquitt JA, LePine JA, Noe RA. Toward an integrative theory of training motivation: A meta-analytic path analysis of 20 years of research. Journal of Applied Psychology. 2000;85(5):678.

59. Noe RA. Trainees' attributes and attitudes: Neglected influences on training effectiveness. Academy of Management Review. 1986;11(4):736-749.

60. Henning MA, et al. Asian medical students: Quality of life and motivation to learn. Asia Pacific Education Review. 2011;12(3): 437-445.

61. Jenkins $A$, Mostafa $T$. The effects of learning on wellbeing for older adults in England. Ageing \& Society. 2015;35(10): 2053-2070.

62. Karen Van $\mathrm{P}$, et al. Student perception as moderator for student wellbeing. Social Indicators Research. 2007;83(3):447.

63. Hicks WD. The process of entering training programs and its effects on training outcomes. The Ohio State University; 1983.

64. Van Petegem K, et al. Student perception as moderator for student wellbeing. Social Indicators Research. 2007;83(3):447-463.

65. Bailey TH, Phillips LJ. The influence of motivation and adaptation on students' subjective well-being, meaning in life and academic performance. Higher Education 
Research \& Development. 2016;35(2): 201-216.

66. Kaufman JC, Agars MD, Lopez-Wagner MC. The role of personality and motivation in predicting early college academic success in non-traditional students at a Hispanic-serving institution. Learning and Individual Differences. 2008;18(4):492496.

67. Ryan RM, Deci EL. Self-determination theory and the facilitation of intrinsic motivation, social development, and wellbeing. American Psychologist. 2000;55(1): 68.

68. Hachem H, Vuopala E. Older adults, in Lebanon, committed to learning: Contextualizing the challenges and the benefits of their learning experience. Educational Gerontology. 2016;42(10): 686-697.

69. Nikolova I, et al. Well-being in times of task restructuring: The buffering potential of workplace learning. Work \& Stress. 2014; 28(3):217-235.

70. Gross R. Psychology: The science of mind and behaviour $7^{\text {th }}$ edition. Hodder Education; 2015.

71. Cunningham J, Hillier E. Informal learning in the workplace: Key activities and processes. Education + Training. 2013; 55(1):37-51.

72. Perkins $\mathrm{R}$, Williamon $\mathrm{A}$. Learning to make music in older adulthood: A mixedmethods exploration of impacts on wellbeing. Psychology of Music. 2014; 42(4):550-567.

73. Gollwitzer PM. Implementation intentions: Strong effects of simple plans. American Psychologist. 1999;54(7):493.

74. Loft $\mathrm{MH}$, Cameron LD. Using mental imagery to deliver self-regulation techniques to improve sleep behaviors. Annals of Behavioral Medicine. 2013;46(3): 260-272.

75. Budden JS, Sagarin BJ. Implementation intentions, occupational stress, and the exercise intention-behavior relationship. Journal of Occupational Health Psychology. 2007;12(4):391.

76. Bélanger-Gravel A, Godin G, Amireault S, A meta-analytic review of the effect of implementation intentions on physical activity. Health Psychology Review. 2013; 7(1):23-54.

77. Hagger MS. Implicating self-control in the mechanism by which implementation intentions reduce stress-induced unhealthy eating: A comment on O'Connor et al. Annals of Behavioral Medicine. 2015;49(3): 301-304.

78. Grothues J, et al. Intention to change drinking behaviour in general practice patients with problematic drinking and comorbid depression or anxiety. Alcohol and Alcoholism. 2005;40(5):394-400.

79. Pasikowski T, Sek H, Ziarko M. Health oriented goals, self-regulatory processes, health behaviors, and well-being. Polish Psychological Bulletin. 2005;1(36):25-33.

80. Hattar A, Pal S, Hagger MS. Predicting physical activity-related outcomes in overweight and obese adults: A health action process approach. Applied Psychology: Health and Well-Being. 2016; 8(1):127-151.

81. Lyubomirsky S, Sheldon KM, Schkade D. Pursuing happiness: The architecture of sustainable change. Review of General Psychology. 2005;9(2):111.

82. Festinger L. A theory of cognitive dissonance. Stanford University Press; 1957.

83. Weisweiler S, et al. Gaining insight to transfer of training through the lens of social psychology. Educational Research Review. 2013;8:14-27.

84. Palsane MN. Self-incongruent behaviour, stress and disease. Psychological Studies-University of Calicut. 2005;50(4): 283.

85. Suinn RM. Anxiety and cognitive dissonance. The Journal of General Psychology. 1965;73(1):113-116.

86. Festinger L. A theory of cognitive dissonance. Stanford University Press. 1962;2.

87. Burisch M. Approaches to personality inventory construction: A comparison of merits. American Psychologist. 1984;39(3): 214.

88. Wanous JP, Reichers AE, Hudy MJ. Overall job satisfaction: How good are single-item measures? American Psychological Association; 1997.

89. Rogelberg SG, Stanton JM. Introduction: Understanding and dealing with organizational survey nonresponse. Sage Publications Sage CA: Los Angeles, CA; 2007.

90. Smith AP, Smith H. A short questionnaire to measure wellbeing at work (ShortSWELL) and to examine the interaction between the employee and organisation; 2017. 
91. Pintrich PR. A manual for the use of the Motivated Strategies for Learning Questionnaire (MSLQ); 1991.

92. Machin MA, Fogarty GJ. Perceptions of training-related factors and personal variables as predictors of transfer implementation intentions. Journal of Business and Psychology. 2003;18(1):5171.

93. Levin $D$, et al. Cognitive dissonance as a measure of reactions to human-robot interaction. Journal of Human-Robot Interaction. 2013;2(3):1-17.

94. Burton KD, et al. The differential effects of intrinsic and identified motivation on wellbeing and performance: Prospective, experimental, and implicit approaches to self-determination theory. Journal of Personality and Social Psychology. 2006; 91(4):750-762.

95. Ryan RM, Deci EL. Self-determination theory: Basic psychological needs in motivation, development, and wellness. Guilford Publications; 2017.

96. Muller J. The effects of personal development training on the psychological state of long-term unemployed women. Australian Psychologist. 1992;27(3):176180.

97. Shapira N, Barak A, Gal I. Promoting older adults' well-being through Internet training and use. Taylor \& Francis; 2007.

98. Shim S, Serido J, Tang C. The ant and the grasshopper revisited: The present psychological benefits of saving and future oriented financial behaviors. Journal of Economic Psychology. 2012;33(1):155165.

99. Strickhouser JE, Zell E, Krizan Z. Does personality predict health and well-being? A Metasynthesis. Health Psychology. 2017;36(8):797.
100. Howell RT. et al. Your personality on a good day: How trait and state personality predict daily well-being. Journal of Research in Personality; 2016.

101. Meyer JP, Maltin ER. Employee commitment and well-being: A critical review, theoretical framework and research agenda. Journal of Vocational Behavior. 2010;77(2):323-337.

102. Bridger RS, Kilminster S, Slaven G. Occupational stress and strain in the naval service: 1999 and 2004. Occupational Medicine. 2006;57(2):92-97.

103. Thoresen CJ, et al. The affective underpinnings of job perceptions and attitudes: A meta-analytic review and integration; 2003.

104. Siu OI. Occupational stressors and well-being among Chinese employees: The role of organisational commitment. Applied Psychology. 2002;51(4):527-544.

105. Zickar MJ, Gibby RE, Jenny T. Job attitudes of workers with two jobs. Journal of Vocational Behavior. 2004;64(1):222235.

106. Vince R. The impact of emotion on organizational learning. Human Resource Development International. 2002;5(1):7385.

107. Elangovan A, Karakowsky L. The role of trainee and environmental factors in transfer of training: An exploratory framework. Leadership \& Organization Development Journal. 1999;20(5):268-276.

108. Blume $B D$, et al. Transfer of training: $A$ meta-analytic review. Journal of Management. 2010;36(4):1065-1105.

109. Velada $R$, et al. The effects of training design, individual characteristics and work environment on transfer of training. International Journal of Training and Development. 2007;11(4):282-294. 


\section{APPENDIX}

Table 1. Survey questions and frequencies (\%) in response categories

\begin{tabular}{|c|c|c|c|c|c|c|c|c|c|}
\hline \multicolumn{10}{|c|}{$\begin{array}{l}\text { To what extent does your job have negative characteristics (e.g. high demands; requires a } \\
\text { lot of effort; little consultation on change; role conflict; issues with other members of staff)? }\end{array}$} \\
\hline \multicolumn{8}{|c|}{ Not at all } & \multicolumn{2}{|c|}{ Very much so } \\
\hline 1 & 2 & 3 & 4 & 5 & 6 & 7 & 8 & 9 & 10 \\
\hline 3.3 & 3.8 & 7.1 & 5.7 & 9.5 & 12.4 & 14.3 & 23.8 & 7.6 & 12.4 \\
\hline \multicolumn{10}{|c|}{$\begin{array}{l}\text { To what extent does your job have positive characteristics (e.g. control over what you do or } \\
\text { how you do it; support from colleagues; support from managers; appropriate rewards)? }\end{array}$} \\
\hline \multicolumn{8}{|c|}{ Not at all } & \multicolumn{2}{|c|}{ Very much so } \\
\hline 1 & 2 & 3 & 4 & 5 & 6 & 7 & 8 & 9 & 10 \\
\hline 0.5 & 0.5 & 1.0 & 4.8 & 6.2 & 15.7 & 21.9 & 25.7 & 11.9 & 11.9 \\
\hline \multicolumn{10}{|c|}{$\begin{array}{l}\text { To what extent do you deal with problems in a positive way (e.g. you focus on the problem } \\
\text { and try to solve it; you got social support)? }\end{array}$} \\
\hline \multicolumn{8}{|c|}{ Not at all } & \multicolumn{2}{|c|}{ Very much so } \\
\hline 1 & 2 & 3 & 4 & 5 & 6 & 7 & 8 & 9 & 10 \\
\hline 0 & 0 & 1.0 & 1.0 & 4.8 & 11.9 & 23.8 & 23.3 & 17.6 & 16.7 \\
\hline \multicolumn{10}{|c|}{$\begin{array}{l}\text { To what extent do you deal with problems in a passive way (e.g. avoid them, use wishful } \\
\text { thinking; blame yourself)? }\end{array}$} \\
\hline \multicolumn{8}{|c|}{ Not at all } & \multicolumn{2}{|c|}{ Very much so } \\
\hline 1 & 2 & 3 & 4 & 5 & 6 & 7 & 8 & 9 & 10 \\
\hline 5.7 & 10.5 & 8.6 & 12.4 & 9.5 & 12.9 & 15.2 & 11.4 & 6.2 & 7.6 \\
\hline \multicolumn{10}{|c|}{$\begin{array}{l}\text { Do you think you have a positive personality (e.g. open; conscientiousness; extravert; } \\
\text { agreeable; stable; high self-esteem; optimistic)? }\end{array}$} \\
\hline \multicolumn{8}{|c|}{ Not at all } & \multicolumn{2}{|c|}{ Very much so } \\
\hline 1 & 2 & 3 & 4 & 5 & 6 & 7 & 8 & & 10 \\
\hline 1.4 & 1.4 & 2.4 & 2.9 & 10.0 & 9.0 & 23.3 & 25.2 & 11.9 & 12.4 \\
\hline \multicolumn{10}{|c|}{ Are you a model employee (e.g. helping; courteous; a good sport)? } \\
\hline \multicolumn{8}{|c|}{ Not at all } & \multicolumn{2}{|c|}{ Very much so } \\
\hline 1 & 2 & 3 & 4 & 5 & 6 & 7 & 8 & 9 & 10 \\
\hline 0 & 0 & 1.0 & 1.9 & 6.2 & 12.4 & 21.0 & 25.2 & 18.1 & 14.3 \\
\hline \multicolumn{10}{|c|}{$\begin{array}{l}\text { Are you committed to your organization (e.g. high job satisfaction; a motivated employee } \\
\text { who does not intend to leave)? }\end{array}$} \\
\hline \multicolumn{8}{|c|}{ Not at all } & \multicolumn{2}{|c|}{ Very much so } \\
\hline 1 & 2 & 3 & 4 & & 6 & 7 & 8 & & 10 \\
\hline 1.0 & 1.9 & 1.0 & 5.2 & 10.5 & 11.4 & 16.7 & 22.9 & 13.8 & 15.7 \\
\hline \multicolumn{10}{|c|}{ Well-being } \\
\hline $\begin{array}{l}\text { In li } \\
\text { moc }\end{array}$ & $\begin{array}{l}\text { erally } \\
\text { ppine }\end{array}$ & u hav & high & el of $v$ & |-being & g. hig & atisfac & ; ; p & itive \\
\hline Not & & 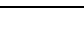 & 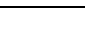 & 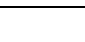 & 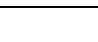 & 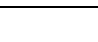 & 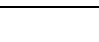 & Very & ich so \\
\hline 1 & 2 & 3 & 4 & 5 & 6 & 7 & 8 & 9 & 10 \\
\hline 1.4 & 1.9 & 2.4 & 3.8 & 6.7 & 11.0 & 22.4 & 26.2 & 11.0 & 13.3 \\
\hline In li & erally & u hav & low I & of $w$ & being & g. str & anx & depres & on)? \\
\hline Not & & & & & & & & Very & ich so \\
\hline 1 & 2 & 3 & 4 & 5 & 6 & 7 & 8 & 9 & 10 \\
\hline 7.1 & 10.5 & 11.4 & 8.6 & 6.2 & 9.5 & 15.2 & 12.9 & 9.5 & 9.0 \\
\hline Trai & ttitud & & & & & & & & \\
\hline $\begin{array}{l}\text { Whe } \\
\text { thos }\end{array}$ & doin & Oi & $\mathrm{urs}$ & is in & $a r$ & ne to & & bei & gh \\
\hline Stro & disagr & & & & & & & Stron & y agree \\
\hline 1 & 2 & 3 & 4 & 5 & 6 & 7 & 8 & 9 & 10 \\
\hline 0.5 & 0.5 & 1.9 & 0.5 & 4.3 & 7.1 & 20.5 & 21.9 & 16.2 & 26.7 \\
\hline
\end{tabular}




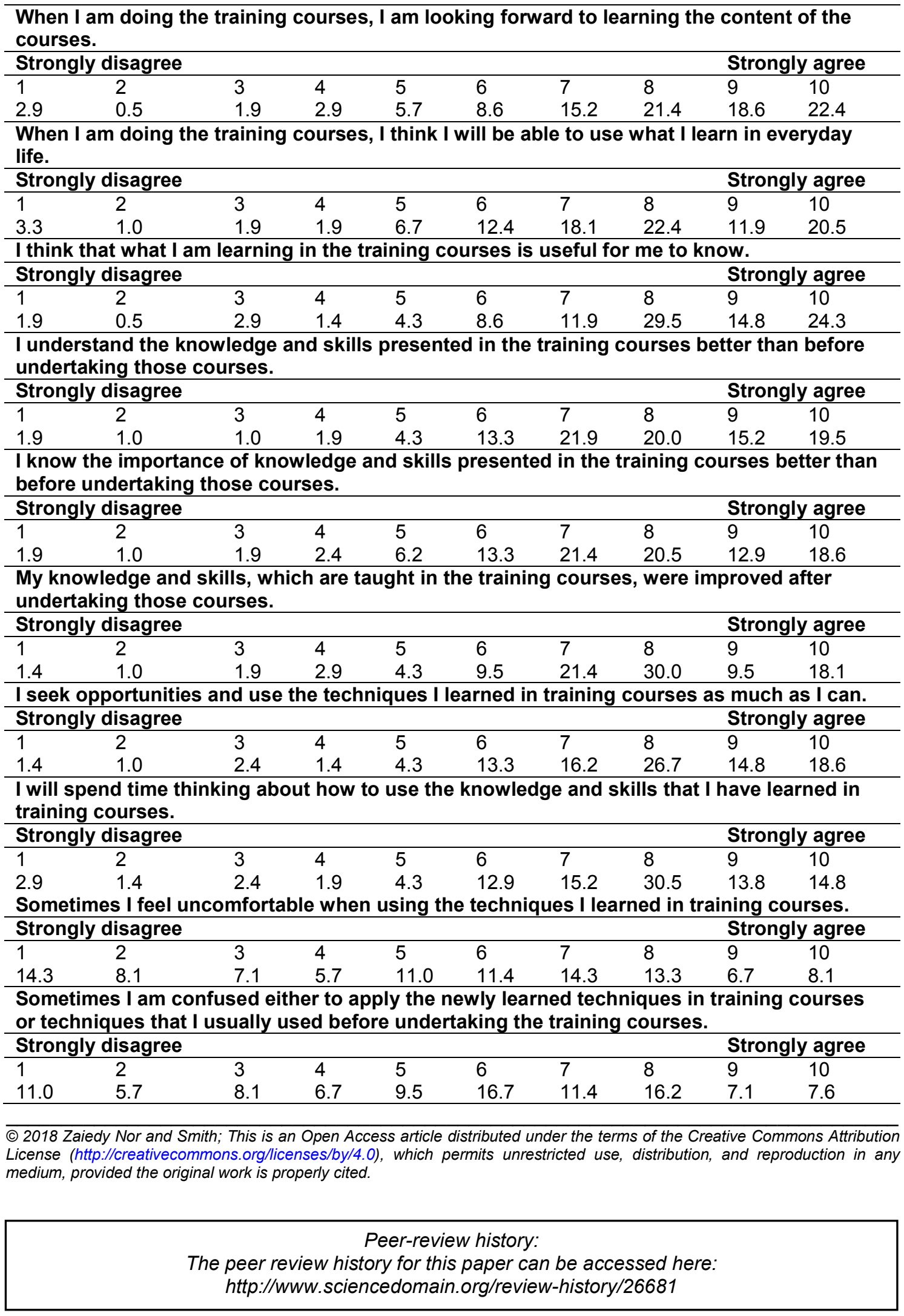

